\title{
Trabalhando noções de tempo e espaço em uma classe hospitalar
}

\author{
Teaching notions of time and space in a hospital classroom \\ Nociones funcionales de tiempo y espacio en el aula de un hospital
}

Recebido: 22/11/2021 | Revisado: 29/11/2021 | Aceito: 30/11/2021 | Publicado: 11/12/2021

Eunice Cajango

ORCID: https://orcid.org/0000-0002-2195-8117

Secretaria Estadual de Educação do Pará, Brasil E-mail: Eunice.cajango@escola.seduc.pa.gov.br

Elielson Sales

ORCID: https://orcid.org/0000-0001-6242-582X Universidade Federal do Pará, Brasil E-mail: esales@ufpa.br

\begin{abstract}
Resumo
O presente estudo tem como objetivo refletir sobre a emergência da comunicação matemática, a partir de atividade intitulada "Meu dia, minhas atividades", desenvolvida em uma classe hospitalar localizada em Belém e vinculada à Secretaria de Educação do Pará. O espaço investigado atende, prioritariamente, a vítimas de acidente com motor ou eixos de motor de embarcação, ocasionando a retirada abrupta parcial ou total do couro cabeludo. A atividade teve como objetivo dialogar sobre conceitos introdutórios de medidas de tempo, relacionando-as a atividades cotidianas das estudantes em suas localidades de origem e no ambiente hospitalar. A pesquisa se caracteriza como qualitativa e os dados foram analisados à luz da perspectiva participacionista de comunicação interpessoal. Participaram da atividade duas alunas, de 10 e 12 anos, cursando o $3^{\circ}$ e $4^{\circ}$ anos do Ensino Fundamental, respectivamente. Compreendemos que a metodologia dialógica adotada para realização da atividade incentivou o engajamento das participantes, possibilitando a individualização do discurso matemático a partir do enfoque participacionista e legitimando a comunicação das estudantes nas modalidades oral e escrita. Por fim, ressaltamos a importância do incentivo e suporte institucional à atuação de professores, acadêmicos e pesquisadores em ambientes tidos como nãousuais para a escolarização formal, de modo a garantir que o direito fundamental de acesso à educação seja assegurado a crianças e adolescentes em tratamento de saúde.
\end{abstract}

Palavras-chave: Educação matemática; Classe hospitalar; Unidades de medida.

\begin{abstract}
This study aims to reflect on the emergence of mathematical communication, from an activity entitled "My day, my activities", developed in a hospital class located in Belém and linked to the Department of Education of Pará. , to victims of accidents with a vessel's engine or motor shafts, causing the abrupt partial or total removal of the scalp. The activity aimed to discuss introductory concepts of time measurements, relating them to daily activities of students in their places of origin and in the hospital environment. The research is characterized as qualitative and the data were analyzed in the light of the participationist perspective of interpersonal communication. Two students, aged 10 and 12 , attending the 3rd and 4th years of Elementary School, respectively, participated in the activity. We understand that the dialogic methodology adopted to carry out the activity encouraged the engagement of the participants, enabling the individualization of the mathematical discourse from a participationist approach and legitimizing the communication of students in oral and written modalities. Finally, we emphasize the importance of institutional encouragement and support for the work of teachers, academics and researchers in environments considered unusual for formal schooling, in order to guarantee that the fundamental right of access to education is ensured to children and adolescents in Health treatment.
\end{abstract}

Keywords: Mathematics education; Hospital class; Measures.

\section{Resumen}

Este estudio tiene como objetivo reflexionar sobre el surgimiento de la comunicación matemática, a partir de una actividad titulada "Mi día, mis actividades", desarrollada en un aula hospitalaria ubicada en Belém y vinculada al Departamento de Educación de Pará., A víctimas de accidentes con embarcaciones motor o ejes de motor, provocando la eliminación abrupta parcial o total del cuero cabelludo. La actividad tuvo como objetivo discutir conceptos introductorios de la medición del tiempo, relacionándolos con las actividades diarias de los estudiantes en sus lugares de origen y en el entorno hospitalario. La investigación se caracteriza por ser cualitativa y los datos fueron analizados a la luz de la perspectiva participacionista de la comunicación interpersonal. En la actividad participaron dos alumnos de 10 y 12 años de $3^{\circ}$ y $4^{\circ}$ de Bachillerato respectivamente. Entendemos que la metodología dialógica adoptada para la realización de la actividad incentivó el involucramiento de los participantes, posibilitando la individualización del 
discurso matemático desde un enfoque participacionista y legitimando la comunicación de los estudiantes en modalidades oral y escrita. Finalmente, destacamos la importancia del estímulo y apoyo institucional al trabajo de docentes, académicos e investigadores en ambientes considerados inusuales para la escolarización formal, a fin de garantizar que se asegure el derecho fundamental de acceso a la educación a la niñez y adolescencia en tratamiento de Salud.

Palabras clave: Educación matemática; Clase de hospital; Unidades de medida.

\section{Introdução}

Pesquisadores de diferentes linhas de investigação têm se dedicado a realizar estudos sobre atividades recreacionais, lúdicas e pedagógicas voltadas a crianças e adolescentes com histórico de internação hospitalar ou necessidade de acompanhamento médico periódico pelo Sistema Único de Saúde (SUS). A característica multidisciplinar do atendimento a esses jovens pacientes, que supõe a integralidade da assistência à sua saúde, caracteriza os ambientes onde tais ações se efetivam como cenários de atuação para profissionais de diferentes campos de atuação - tanto das já estabelecidas ciências da saúde como da recém-chegada área da educação, além das humanas e sociais (Barroset et al., 2011).

O serviço de classe hospitalar e atendimento pedagógico domiciliar, instituído em 1991 pelo Ministério da Educação, tem assumido papel de destaque nesse panorama. Trata-se de uma modalidade de atendimento prestada a educandos de diferentes faixas etárias internados em hospitais, casas de apoio ou contextos domésticos adaptados à assistência médica. Como destacam Holanda e Collet (2011), a oferta de tal serviço parte do reconhecimento de que o cuidado a esses pacientes deve contemplar suas necessidades ampliadas em saúde, quais sejam: emocionais, sociais, familiares, culturais e ambientais. Assim, as ações pedagógicas devem ser sistematizadas com vistas à continuidade de estudos durante o tratamento médico e após a alta hospitalar (Covic \& Oliveira, 2011).

O objetivo de tais atividades não se resume a possibilitar a continuidade de sua trajetória escolar após a alta hospitalar, minimizando assim os impactos em seu desempenho acadêmico e prevenindo possíveis déficits no seu processo formativo. Para além disso, as ações pedagógicas representam um componente da rotina infantil e juvenil notadamente relacionado à sua participação social e à constituição de sua autoestima (Batista et al, 2009). Mendes (2002) destaca que o acompanhamento pedagógico ao escolar em saúde contribui para a garantia de integralidade na assistência à saúde, visando o bem-estar desses indivíduos.

Em que pesem os marcos legais de reconhecimento ao direito inalienável desses jovens aprendizes e a expansão gradual na oferta de classes hospitalares, ainda são reconhecidamente complexos os desafios enfrentados pelos atores envolvidos nesse movimento: educadores, equipe multidisciplinar, família e, principalmente, dos aprendizes que se encontram temporariamente impossibilitados de frequentar a escola regular e se veem privados do convívio social com seus pares em desenvolvimento intelectual e cognitivo. Observados os indicativos historicamente consolidados de segregação escolar, o atendimento voltado a estudantes em tratamento de saúde (seja ele realizado por meio de internação, ou na configuração hospital-dia, hospital-semana ou na atenção integral à saúde mental) constitui temática importante, na medida em que evidencia a realidade de considerável número educandos que precisam se submeter a intervenções clínicas de forma prolongada ou contínua.

Pioneiro na oferta de serviços pedagógicos a indivíduos em tratamento de saúde no Estado do Pará, o Hospital Ophir Loyola (HOL) teve, como destacado por Saldanha (2012), ações embrionárias de caráter lúdico e recreativo iniciadas por uma assistente social em 1993. O crescente interesse das crianças em tratamento oncológico motivou, posteriormente, atividades de escolarização realizadas por uma pedagoga, também funcionária do hospital (Lacerda \& Silva, 2015). Em 2002, a implantação de um Convênio de Cooperação Técnica entre Secretaria de Estado de Educação (SEDUC) e HOL conferiu ao serviço de atendimento educacional hospitalar legalidade e estruturação, nos moldes previstos pela Resolução CNE/CEB no 2 de 11 de setembro de 2001. 
$\mathrm{Na}$ esteira dessa iniciativa, somaram-se outros acordos realizados entre a SEDUC - responsável pelo aporte de profissionais (pedagogos, licenciados plenos e fonoaudiólogos) e pelo material escolar - e instituições públicas com atendimento ambulatorial, hospitalar ou com configurações de casas de apoio, que assumem como contrapartida a cessão de espaços adequados às atividades de escolarização, bem como a manutenção dos espaços em condições adequadas de higiene e segurança.

Vasconcelos (2015) ressalta como um importante aspecto da formação docente para o atendimento de estudantes em contextos hospitalares ou domiciliares adaptados uma conversação de qualidade entre professor e aluno, de modo a possibilitar a aprendizagem de objetos do conhecimento por meio do diálogo e da escuta mútua, relacionando os saberes escolares a situações concretas, reconhecidas no cotidiano desses indivíduos, e dando condições para que os estudantes consolidem diversifiquem suas estratégias comunicacionais.

Alrø e Skovsmose (2006), por sua vez, destacam a dificuldade encontrada por muitos professores que têm "grande simpatia com alguma forma de ensino inovadora" (Alrø \& Skovsmose, 2006, p. 26) para colocar em prática tais ideias, em virtude de se encontrarem em ambientes escolares engessados por um absolutismo burocrático. Segundo os autores, tal modalidade de absolutismo está entranhada nas estruturas básicas de comunicação em sala de aula e estabelece, a partir de concepções epistemológicas implícitas, "em termos absolutos o que é certo e o que é errado sem explicitar os critérios que orientam tais decisões" (idem).

No caso dos ambientes hospitalares onde se configuram ações pedagógico-educacionais, aos obstáculos de ordem metodológica e curricular - uma vez que se faz necessária a interlocução com o planejamento da escola de origem dos educandos - somam-se as fragilidades de ordem física e psicoemocionais desses mesmos educandos, que precisam ser igualmente consideradas ao longo de todo o processo.

Diante do exposto, o presente estudo busca apresentar reflexões sobre a emergência de comunicação matemática, a partir da perspectiva participacionista, em uma classe hospitalar multisseriada vinculada à Fundação Santa Casa de Misericórdia do Pará (FSCMP). Para tanto, descrevemos uma sequência de ensino sobre padrões de medidas de comprimento, desenvolvidas junto a educandas do $3^{\circ}$ e $4^{\circ}$ anos do Ensino Fundamental, que buscou dialogar sobre noções introdutórias de mensuração e padronização de intervalos de tempo.

\section{Metodologia}

Considerando o objetivo da pesquisa, assumimos uma abordagem metodológica qualitativa, pautados nos pressupostos de Bogdan e Biklen (1994), que a definem como um conjunto de estratégias de investigação que possibilitam a constituição de um processo de reflexão e análise da realidade observada. Ainda segundo os autores, os dados constituídos em um ambiente natural educativo são potencialmente ricos em caracterizações do contexto e dos atores envolvidos.

Tal configuração confere ao investigador a responsabilidade de observar e caracterizar em pormenores todo o processo investigativo, ao invés de ressaltar apenas os resultados, com vistas a amparar uma interpretação legítima e fidedigna dos fatos constituídos no decorrer da pesquisa. A atividade educacional foi desenvolvida em uma classe hospitalar localizada em Belém e vinculada à Secretaria de Educação do Pará, por meio de convênio estabelecido junto à FSCMP.

Localizada em espaço criado pela FSCMP com o objetivo de prestar assistência integrada a pacientes em tratamento na capital paraense (Beckman \& Santos, 2010), a classe atende, em caráter prioritário, a vítimas de escalpelamento acidental por motor ou eixos de motor de embarcação (Cunha et al, 2012), que necessitam se deslocar de seu município de origem para realizar tratamento específico para as lesões decorrentes do acidente (Brasil, 2015). As ações referentes à pesquisa foram elaboradas e desenvolvidas pela primeira autora, sob orientação do segundo autor, ao longo de dois dias, em sessões de 90 minutos cada, com duas alunas de 10 e 12 anos, cursando o $3^{\circ}$ e $4^{\circ}$ anos, respectivamente. 
A atividade em questão, intitulada "Meu dia, minhas atividades", compôs um conjunto de ações que visaram amparar uma tese de doutorado sobre educação matemática para estudantes em tratamento de saúde, com projeto aprovado junto ao Comitê de Ética em Pesquisa da Universidade Federal do Pará, sob o parecer de número 3.529.052. Os termos de consentimento livre e esclarecido foram assinados pelos responsáveis legais das participantes, que, por sua vez, concordaram em participar espontaneamente da pesquisa, assinando os termos de assentimento livre e esclarecido.

Visando atender aos princípios éticos, as estudantes envolvidas nos diálogos serão identificadas pelas letras E1 e E2, e as manifestações orais da professora-pesquisadora serão evidenciadas por Prof.

\section{Resultados e Discussão}

O processo de aprendizagem pode ser definido, a partir de uma ótica aquisicionista (Sfard, 2006) como um conjunto estruturado de ações conscientes que possibilitam a um indivíduo a se engajar em um movimento coletivo somente após suas aquisições pessoais. Tal perspectiva, que se ampara em estudos do epistemólogo suíço Jean Piaget, entre outros, assume as capacidades humanas como constituições essencialmente fisiológicas, ainda que, em alguma medida, influenciada por fatores sociais.

O enfoque participacionista (Sfard, 2006), por sua vez, tem como princípio o reconhecimento da variabilidade dos processos de aprendizagem, a partir das singularidades inerentes aos diversos contextos em que estes ocorrem. Isso justificaria, segundo tal pressuposto, a heterogeneidade da evolução humana ao longo das gerações, tendo como base "uma mistura de abordagens, em vez de um único discurso de investigação" (Sfard, 2006, p.158, tradução nossa). Ainda a partir dessa perspectiva, uma pessoa pode passar a desenvolver atividades como cozinhar ou solucionar problemas matemáticos por si só apenas após participar de atividades socialmente implementadas, em um movimento fluido e dialético. Os termos "individualização" e "coletivização" são designados por Sfard (2006) para atribuir sentidos ontologicamente indistintos e homogêneos para os conceitos de pensamento e comportamento.

Segundo a autora, a individualização toma forma nas atividades particulares que uma pessoa desenvolve a partir de ações padronizadas do coletivo, e sua essência reside na capacidade humana de ressignificar os papéis dos seus semelhantes. Sfard (2006), que define pensamento como uma atividade coletiva padronizada e não como uma atividade aprioristicamente individual, compreende a comunicação interpessoal como uma característica que torna os seres humanos sociais.

A partir de tais perspectivas, Sfard defende a troca do restritivo termo discurso para o termo mais generalizante comunicação (seja ela referente à comunicação interpessoal ou à autocomunicação), assumindo que as regras que regulam a comunicação residem em costumes historicamente estabelecidos, cuja natureza é contingencial, com regras orientadas e dinâmica própria. Ainda segundo a autora, um discurso se apresenta na forma de matemática quando apresenta as seguintes "regras": palavras matemáticas, mediadores visuais específicos (como artefatos simbólicos criados para esta forma de comunicação), narrativas endossadas (que se relacionam com as chamadas teorias matemáticas), e/ou rotinas (padrões repetitivos característicos de um dado discurso). A partir de tais definições, a aprendizagem matemática pode ser compreendida sob o enfoque participacionista como a individualização do discurso matemático, isto é, como o processo de se tornar capaz de ter uma comunicação matemática não só com os outros, mas também consigo mesmo (Sfard, 2006).

Sfard (2006) destaca tal processo como um motor de arranque para a criatividade do indivíduo, sendo a proficiência neste discurso (como em qualquer outro) um pré-requisito para a sua individualização por parte do educando. Assim, a comunicação com interlocutores experientes passa a constituir o ponto de partida para a mudança discursiva em matemática, uma vez que essa inter-relação implicará em conflitos comunicacionais que, segundo a autora, provavelmente resultarão em um processo de aprendizagem matemática. 
Diante desses pressupostos, buscamos refletir sobre a emergência da comunicação matemática, por entendermos tal processo como particularmente significativo para estudantes de classes hospitalares, que se encontram temporariamente afastados do convívio com professores e colegas de sua escola de origem, e que têm no diálogo um veículo para a constituição de novos conhecimentos matemáticos.

A atividade proposta contou com dois momentos específicos e buscou problematizar, os conceitos introdutórios de medidas de tempo (Roazzi \& Castro Filho, 2001), explorando questões relacionadas à compreensão, interpretação, registro e comunicação das ações cotidianas das alunas em certos períodos (manhã, tarde e noite) e dados ambientes (localidade de origem e contexto hospitalar). Para auxiliar nesse processo, utilizamos objetos manipuláveis, como calendários, relógios e o globo terrestre, além da interpretação de desenhos e vídeos ilustrativos da passagem do tempo segundo diferentes referenciais, como o sol e a lua. Tais recursos possibilitaram às alunas a visualização e compreensão das conjecturas de natureza social e científica que deram origem à padronização de medidas de tempo por diferentes civilizações ao longo da história (Gonçalves et al, 2007).

Considerando o nível educacional das estudantes $\left(3^{\circ}\right.$ e $4^{\circ}$ anos), nos delimitamos a introduzir o conceito de medidas de tempo (Roque, 2012), apresentando a possibilidade de indicar um determinado momento do dia por meio da menção oral ou do registro de horas e minutos. Adicionalmente, buscamos destacar as características e aplicações no cotidiano das relações observadas na manipulação dos objetos e nos recursos audiovisuais utilizados. A atividade contou com dois momentos distintos, descritos a seguir. Inicialmente, solicitamos às alunas que relatassem as atividades cotidianas que elas realizavam todos os dias em sua localidade de origem e no contexto hospitalar.

Em seguida, as questionamos se haveria uma hora certa para realizar tais atividades. Elas, então, descreveram algumas das ações que vinculadas a um determinado horário ou período, estipulado previamente.

E1: Pra tomar banho, tem que ser só de manhã e de tarde. Porque de noite dá muito boto no rio, e eles ficam querendo malinar com a gente. Só se for da caixa (d'água).

E2: Antes da pandemia, tinha que ir pro colégio todo dia na mesma hora. (...) Depois, era só fazer os trabalhos que a tia deixava (no domicílio da estudante). Então podia ser qualquer hora, mas eu fazia sempre à noite, depois da janta.

E1: Tem também os remédios, que a gente tem que tomar sempre na mesma hora, né?! (...) Cada um tem uma hora pra tomar (...), e não pode esquecer, senão piora (a cicatrização das lesões ou o controle das infecções delas decorrentes).

Como assinalado por Sfard (2006), a criança imersa em um dado contexto gradualmente incorpora as atividades sociais ali compartilhadas ao seu próprio pensamento e comportamento. Assim, essa criança passa a assumir as ações coletivamente padronizadas como tarefas individuais que devem ser realizadas de forma consciente, sob o risco de sofrer sanção (como tomar uma advertência escolar) ou algum tipo de prejuízo, inclusive de saúde.

$\mathrm{Na}$ sequência da atividade, apresentamos às alunas vídeos e ilustrações direta ou indiretamente relacionados à temática de mensuração do tempo, como, por exemplo, o conhecimento historicamente constituído por diferentes povos a respeito de astronomia e de fenômenos naturais, como a aurora boreal e o fluxo das marés. Ao explicar sobre os movimentos de translação (órbita elíptica que a Terra percorre, completando uma volta ao redor do Sol no período de 365 dias, 5 horas e 48 minutos) e de rotação (movimento que a Terra realiza em torno de seu próprio eixo), convidamos as alunas a manipular o 
globo terrestre, de modo a conjecturarem a relação entre a localização de um dado país e a alternância entre dias e noites, a partir da incidência de raios solares sobre ele.

Na sequência, solicitamos às participantes que registrassem de forma escrita as atividades de seu cotidiano que elas realizavam com regularidade, em cada período do dia. As atividades foram classificadas em dois campos: um referente à localidade de origem de cada aluna, e outro referente ao espaço onde estavam acolhidas para realizar o tratamento de saúde na capital. Observamos que a estudante de 10 anos de idade apresentou dificuldades para redigir detalhadamente as atividades que relatou no diálogo. Embora ela estivesse cursando o $3^{\circ}$ ano na escola regular, suas sentenças oralizadas no momento anterior foram resumidas, na modalidade escrita, a palavras-chave, como casa e caixa, e, até mesmo para escrever algumas dessas expressões, a estudante solicitou auxílio à professora-pesquisadora.

Tal ocorrência corresponde a uma realidade destacada em estudos como o de Cardoso e Jacomeli (2010) e ainda comumente observada em alunos dos primeiros anos do Ensino Fundamental, cujo processo de letramento muitas vezes não corresponde ao nível esperado para a etapa de escolarização na qual os mesmos se encontram matriculados (Azevedo, 2019), resultando em dificuldades adicionais para que esses estudantes compreendam conceitos e até mesmo orientações docentes para a realização de atividades que supõem leitura, interpretação e redação textual (Souza; Miguel, 2020).

Ressaltamos que fenômeno semelhante ocorre no âmbito da educação matemática, que tem seus objetos do conhecimento, competências e habilidades elencados em documentos curriculares oficiais do MEC - Base Nacional Comum Curricular (BNCC) - e da Secretaria Estadual de Educação - Documento Curricular para Educação Infantil e Ensino Fundamental do Estado do Pará. Adicionalmente, pudemos observar que, com a suspensão das aulas presenciais em decorrência do agravamento da pandemia de COVID-19 a partir de março de 2020, a qual se estendeu ao longo do primeiro semestre letivo de 2021, as crianças cujos responsáveis não tiveram acesso a um nível mais avançado de instrução formal foram particularmente prejudicadas no acompanhamento para realização das tarefas remotas.

Esse foi o caso da participante da pesquisa, cujos pais, analfabetos, só haviam aprendido a assinar o primeiro e último nome em seus documentos de identidade. Na etapa final de desenvolvimento da atividade, buscamos apresentar às educandas, a partir da manipulação de um relógio analógico do tipo despertador, a correspondência entre a abertura dos ponteiros que representam horas e minutos e o conceito geométrico de ângulos. Como esse não era um dos objetivos intrínsecos à atividade, no entanto, nos detivemos apenas na noção inicial do conceito, sem detalharmos as classificações de tais ângulos e suas respectivas medidas.

Como destacado por Sfard (2006), quando um interlocutor mais experiente manifesta um discurso na forma matemática, com linguagem, mediadores visuais e narrativas características dessa área de conhecimento, a comunicação desse interlocutor com o aprendiz possibilita a este último a composição de um repertório com vistas a subsidiar uma futura proficiência nessa mesma área. Solicitamos, na sequência, que as participantes registrassem, por meio de desenho representativo de um relógio analógico, os horários referentes à realização de duas atividades de suas rotinas (uma delas listada no cotidiano de sua localidade de origem e a outra, no campo vinculado ao ambiente que abriga a classe hospitalar).

Seguindo as orientações para diferenciação dos ponteiros através do comprimento dos mesmos, ambas as alunas recorreram à manipulação do relógio analógico, com utilização da função despertador para dirimir a dúvida sobre qual ponteiro deveria ser mais extenso: o das horas ou dos minutos. Ao fazer isso, as participantes reproduziram a estratégia descrita pela professora-pesquisadora para esse tipo de esclarecimento: como o despertador analógico, representado por um relógio em miniatura dento do relógio maior, só conta com um ponteiro, dada uma determinada hora em ponto, o ponteiro referente àquele determinado horário estará posicionado, no visor maior, exatamente em cima do número que indica a hora.

Assim, conforme apontado por Sfard (2006), as estudantes, adequando-se à dinâmica própria da comunicação estabelecida de forma orientada para a atividade, conduziram seus pensamentos em direção a uma ação coletiva padronizada, 
qual seja, a de representar determinado horário do dia pelo ângulo formado por um ponteiro mais curto e outro mais longo, indicando horas e minutos daquele dia. Por fim, solicitamos às participantes que explicassem por que haviam escolhido aquele determinado horário e aquela atividade específica para indicar no relógio desenhado.

E1: Eu escolhi nove horas, que é o que eu faço de manhã aqui (estudar). Também escolhi a hora da comida (almoço, às 12:30) na minha casa, que eu fico vendo televisão.

E2: Eu coloquei oito horas, eu vejo televisão lá (em casa), de manhã e de noite, também. E aqui (para o ambiente hospitalar) eu fiz seis horas, que é a hora que a minha mãe me acorda, pra tomar remédio.

Para encerrarmos a atividade, realizamos uma breve dinâmica com as estudantes, para que elas avaliassem a ação pedagógica desenvolvida e sua própria motivação, tanto para o estudo, quanto para realizar as atividades de caráter pessoal que listaram ao longo do processo, como tomar banho de rio, indicado pela participante de 10 anos, e dar continuidade ao curso de informática, citado pela aluna de 12 anos de idade.

\section{Considerações Finais}

No cotidiano da escolar regular, ainda observamos alunos que realizam tarefas matemáticas cujo significado se restringe à execução de comandos ou repetição de procedimentos padronizados, que, como destacado por Loss (2014), pouco contribuem para o desenvolvimento de suas habilidades comunicacionais e relacionais. Em se tratando de classes hospitalares, cujos alunos se encontram privados da rotina de socialização com seus pares no ambiente da escola regular, a limitação das práticas pedagógicas a tais procedimentos, para além de não privilegiar a participação espontânea desses estudantes, pode desestimulá-los a reconhecer em tais atividades uma oportunidade para o diálogo e para o exercício de sua capacidade criativa (Marchesan et al, 2009).

Por outro lado, ao se envolver em ações compartilhadas de forma espontânea, orientadas por um mediador mais experiente e proficiente no discurso matemático, os aprendizes têm a oportunidade de constituir conhecimentos escolares sem comprometer a sociabilidade inerente à aprendizagem humana. Embora o discurso da professora-pesquisadora tenha sido pautado por regras e padrões específicos do campo da matemática, o envolvimento das estudantes com a atividade proposta possibilitou que os objetos do conhecimento escolar fossem por elas enredados de modo que as mesmas puderam legitimar estratégias comunicacionais relacionadas à sua rotina de vida (tanto em casa, como no ambiente hospitalar).

Assim, no decorrer da atividade, as participantes trilharam o caminho da individualização desses discursos a partir de seu repertório e de suas vivências, incorporando-os à sua concepção de mundo e atualizando a sua compreensão de escola. Em ambientes nos quais muitas vezes o desânimo e a indisposição fazem parte da rotina do tratamento médico de crianças e adolescentes, compreendemos como particularmente relevantes ações integradas que privilegiem a constituição de conhecimentos escolares de modo a valorizar a emergência da comunicação matemática junto a tais estudantes.

Consideramos que, como apontado por Castro et al. (2021), desempenham papel de fundamental importância as investigações que propõem reflexões sobre as singularidades e vivências de estudantes em tratamento de saúde. Tais estudos, aliados a futuras investigações sobre o que esses jovens aprendizes relatam a respeito de seu próprio processo de aprendizagem, consolidam o seu direito inalienável de crianças e adolescentes à educação e à saúde em sua perspectiva integral, ampliando os debates a respeito das necessárias ações institucionais visando assegurar e ampliar essa assistência em âmbito nacional. 


\section{Referências}

Alrø, H. \& Skovsmose, O. (2006). Diálogo e aprendizagem em educação matemática. Ed. Autêntica.

Azevedo, S. A. A. (2019). O desafio de argumentar nas aulas de Matemática: uma investigação com estudantes do $1^{o}$ ano do Ensino Fundamental. (Dissertação de mestrado). Pontifícia Universidade Católica de São Paulo. 259f. https://tede.pucsp.br/bitstream/handle/22665/2/Simone \%20Aparecida\%20dos\%20Anjos\%20 Azevedo.pdf.

Barros, A. S. S., Gueudeville, R. S. \& Vieira, S. C. (2011). Perfil da publicação científica brasileira sobre a temática da classe hospitalar. Revista Brasileira de Educação Especial. 17(2), 335-354. http://www.scielo.br/scielo.php?script=sci_arttext\&pid=S1413-5382011000200011.

Batista, A. V. et al. (2009). A práxis pedagógica no ambiente hospitalar: perspectivas e desafios. Pedagogia em ação. 37. PUC Minas. http://pucmg.br/graduacao/cursos/arquivos/ARE_ARQ_REVIS_ELETR20120912121103.pdf?PHPSESSID=8db60cf9fcdb7a4d3c9983fc1b79fc11.

Beckman, K. A. F. \& Santos, N. C. M. (2010). Terapia Ocupacional: relato de caso com vítima de escalpelamento por eixo motor de barco. Cadernos Brasileiros de Terapia Ocupacional. 12 (1). http://www.cadernosdeterapiaocupacional.ufscar.br/index.php/cadernos/article/viewFile/189/145.

Brasil. (2015). Capitania dos Portos da Amazônia Oriental. Palestra de Prevenção ao Escalpelamento. Marinha do Brasil. https://www.mar.mil.br/cpaor/arquivos/escalpelamento.pdf .

Brasil. (2002). Ministério da Educação. Classe hospitalar e atendimento pedagógico domiciliar: estratégias e orientações. Secretaria de Educação Especial. Brasília: MEC; SEESP. Disponível em: portal.mec.gov.br/seesp/arquivos/pdf/livro9.pdf .

Cardoso, M. A. \& Jacomeli, M. R. M. (2010). Estado da arte acerca das escolas multisseriadas. Revista HISTEDBR On-line. 10(37e), 174-193. https://periodicos.sbu.unicamp.br/ojs/index.php/histedbr/article/view/8639788.

Castro, J. F., Silva, S. M., Vendrame, E. C. S \& Paula, E. M. A. T. (2021). Educação na pandemia: jogos e brincadeiras on-line com crianças em tratamento de saúde. Research, Society and Development. 10(14). https://rsdjournal.org/index.php/rsd/article/view/21763.

Covic, A. N. \& Oliveira, F. A. de M. (2011). O aluno gravemente doente. Ed. Cortez.

Cunha, C. B. et al. (2012). Perfil epidemiológico de pacientes vítimas de escalpelamento tratados na Fundação Santa Casa de Misericórdia do Pará. Revista Brasileira de Cirurgia Plástica. 27(1), p. 3-8. https://www.scielo.br/pdf/rbcp/v27n1/03.pdf.

Holanda, E. R.; Collet, N. (2011). As dificuldades da escolarização da criança com doença crônica no contexto hospitalar. Revista da Escola de Enfermagem da USP. 45(2), p. 381-389, 2011. http://www.scielo.br/pdf/reeusp/v45n2/v45n2a11.

Lacerda, F. B.; Silva, R. F. G. (2015). A classe hospitalar no Pará: implantação e Implementação. Revista Marupiíra. 2, 66-81. https://periodicos.uepa.br/index.php/marupiira/article/view/913.

Loss, A. S. (2014). Para onde vai a pedagogia? os desafios da atuação profissional na pedagogia hospitalar. Ed. Appris.

Marchesan, E. C. et al. (2009). A não-escola: os sentidos atribuídos à escola e ao professor hospitalares por pacientes oncológicos. Psicologia: ciência e profissão. 29, p. 476-493. //www.scielo.br/j/pcp/a/NmLJCr58WBLKDsKgbdwZtCy/?lang=pt.

Mendes, E. G. (2002). Desafios atuais na formação do professor de educação especial. Revista Integração. 24 , 12-17.

Roazzi, A. \& Castro Filho, J. A. de. (2001). O Desenvolvimento da Noção de Tempo como Integração da Distância e da Velocidade. Psicologia: Reflexão e Crítica. 14, p. 497-503. https://www.scielo.br/j/prc/a/yHDBqDDmkmCmWYzg9NDvC6y/?format=pdf\&lang=pt.

Roque, T. (2012). História da matemática. Editora Zahar.

Saldanha, G. M. M. M. (2012). A Educação escolar hospitalar: práticas pedagógicas docentes com crianças em tratamento oncológico no Hospital Ophir Loyola em Belém-PA. (Dissertação de mestrado). Universidade Federal do Pará, Belém. http://200.239.66.58/jspui/handle/2011/2791.

Sfard, A. (2006) Participationist discourse on mathematics learning. New mathematics education research and practice, 153-170.

Souza, E. G.; \& Miguel, A. (2020). A encenação de práticas culturais na tessitura de outras escolas: A vida como eixo da ação educativa. REMATEC. 15(33), p. 166-184. http://rematec.net.br/index.php/rematec/article/view/227.

Vasconcelos, S. M. F. (2015). Histórias de formação de professores para a Classe Hospitalar. Revista Educação Especial. 1(1), 27-40, periodicos.ufsm.br/educacaoespecial/article/. 